\title{
One Giant Step for Humankind
}

\author{
Marvin L. Birnbaum, MD, PhD
}

In the twentieth century, war will be dead, the scaffold will be dead, hatred will be dead, frontier boundaries will be dead, dogmas will be dead; man will live. $\mathrm{He}$ will possess something higher than all these- a great country, the whole earth, and great hope, the whole heaven.

Victor Hugo, The Future of Man
In all of the history of medicine, certain events or discoveries, whether by intent or accident, have contributed to a segment of medical practice establishing itself as a new entity with its own specific science and standards. For disaster medicine, one such event occurred in association with the responses to the earthquake in Armenia in 1988 and another occurred in March 1997 at a Congress assembled by Knut Ole Sundnes at the Nordic School of Public Health in Gothenberg, Sweden. Such events as these are shaping the discipline of Disaster Medicine in its role of minimizing the health impact of disasters on humankind.

Until the last decade, after-action and published reports of the responses generated by disasters to humankind have been anecdotal and descriptive. These reports have contributed much to our understanding of these responses, and have led to significant changes in the conduct of our medical responses to disasters. However, following the Armenia earthquake, investigators first applied in an organized fashion, the techniques of evaluation and epidemiologic research embraced by other social science disciplines. $^{1-4}$ The investigators, including researchers from both the United States and the then Soviet Union, and the outstanding work of Eric Noji from the U.S. Centers for Disease Control and Prevention revolutionized the study and reporting of the medical needs and responses to disasters. These studies forever changed the structure for the conduct of studies of the needs and responses to disasters.

Since these hallmark studies, the quality and volume of scientific research in the areas of needs and disaster responses have exploded. This is evidenced by the fact that since these studies, PDM has published 21 papers and one supplement that have utilized these evaluation and qualitative research techniques. This trend continues with three papers included in this issue. These papers not only have examined scientifically the short-term impacts of such events, but have expanded the scope into the long-term effects that at least are as important as are those associated with the infrastructure failure associated with the disaster (see Koscheyev et al on page 49 in this issue). The volume of such studies now is increasing in the medical literature at a similar rate as are the studies in our companion sciences. In fact, when surfing the Internet for "disasters," "disaster responses," and "disaster medicine," I was able to identify more than 600,000 hits for disaster medicine and a similar number for disaster responses. Only some 200,000 hits were achieved for disasters. Our science associated with disaster responses and disaster medicine is growing exponentially.

With this burgeoning information base, it now is apparent that there is a need for organization of this material as it already is sufficient to overwhelm even the most ambitious of scientists. This issue is addressed by the Piper et al article on page 21 in this issue.

The utility of these new forms for study of this evolving medical science, however, has been limited: much of what is defined in one study that could be applied to mitigation of the impact of future events is lost due to our inability to compare events (different disasters). Thus, it has not been possible to utilize as much information as is possible from such studies. This has been due to our inability to identify common factors associated with dissimilar events. The external validity of such studies has not been realized fully.

This inability to optimize the external validity of such studies only has 
become apparent following the development of the structure for our science. It became clear that there was a need for some standardization of severity and identification of aspects of the responses to all disasters regardless of how dissimilar they may seem. The first attempt to address this issue resulted in the initial draft of the Template for Disaster Medicine Research. Its development was supported by the Norwegian Ministry of Foreign Affairs and the Laerdal Foundation for Acute Care. ${ }^{5}$

The second such event occurred in the Gothenberg Congress. In an effort to refine the Research and Evaluation Template for Medical Responses to Disasters, ${ }^{5}$ a Congress was convened at the Nordic School of Public Health. It was in this remarkable, perfect setting for the conduct of such a working Congress that a giant step was made for the future of Humankind. The Congress was engineered by Knut Ole Sundnes and was attended by 47 participants from 25 countries including representatives from the International Red Cross and Red Crescent, the Organization of African Unity, the World Health Organization, the Department of Humanitarian Affairs of the United Nations, and many of the more knowledgeable participants in the world of disaster responses and humanitarian aid. Again, the Congress was supported by the governments of Norway and Sweden and was graciously hosted by the Nordic School of Public Health.

The objectives established for this august body included the seemingly insurmountable tasks of furthering important aspects of the Template in order to create uniformity from diversity. The tasks included the development of: 1) severity scores for comparisons of the responses to disasters of similar severity regardless of their etiology; 2) severity scores for the medical aspects of a disaster; 3) quantification tools for the comparison of medical responses to disasters; 4) definitions of medical needs for comparison of resources provided versus the actual needs and wants; 5) a vulnerability/preparedness index for the evaluation of the pre-disaster health circumstances; 6) refinements in the methods that can be used for definition of measures of effectiveness and critical pathways that will enhance such evaluations; and 7) the principles of evaluation research. The products achieved constitute a testimony to the nature of the participants who were diverse in culture, background, and expertise. Their work constitutes a profound and essential step in the creation of research techniques and mechanisms for mitigating the effects of a disaster through the organized study of disaster responses. It is because of the efforts of each of these participants that disaster responses, not only for the medical aspects of such responses but for disaster responses in general, will contribute on an ongoing basis to our understanding of the human and environmental phenomena surrounding a disaster. Each of them helped us take a giant step for humanity. Their work constitutes a hallmark event that will forever shape how Humankind responds to the suffering of others.

Humankind is indebted to the governments of Norway and Sweden and to the Laerdal Foundation for Acute Care for their faith in the process and for their support. The work from this Congress will be summarized in the Volume 12, Number 4 (October-December 1997) issue of Prebospital and Disaster Medicine. However, the work is not nearly completed. Much remains to be done to refine, test, and further these important tools. And, given that this is the United Nations' International Decade for the Reduction of Natural Disasters, support for the continuation of this process must come from sources other than the Nordic countries whose commitment and faith have sustained this process thus far. Each such event constitutes a giant step, and the work potentially has a greater impact on humankind than will any other effort directed to this end. Though the end is in sight, many more great steps will be necessary. The process is ongoing and it needs your support, and the support of your organizations.

How beauteous mankind is! O brave new world

That bas such people in it.

William Shakespeare, The Tempest

\author{
References \\ 1. Klain M, Ricci E, Safar P, et al: Disaster reanimatology potentials: A \\ structured interview study in Armenia: I. Methodology and preliminary \\ results. Prehospital and Disaster Medicine 1989;4:135-154. \\ 2. Ricci EM, Pretto EA, Safar P, et al: Disaster reanimatology potentials: A \\ structured interview study in Armenia II. Method for the evaluation of \\ medical response to major disasters. Prehospital and Disaster Medicine \\ 1991;6:159-166. \\ 3. Pretto EA, Ricci E, Klain M, et al: Disaster reanimatology potentials:
}

\footnotetext{
A structured interview study in Armenia. III. Results, conclusions, recommendations. Prebospital and Disaster Medicine 1992;7:327-338.

4. Ricci E, Pretto, E: Assessment of prehospital and hospital response in disaster. Critical Care Clinics 1991;7:471-484.

5. World Association for Disaster and Emergency Medicine: Disaster Medical Response Research: A Template in the Utstein-Style. Prehospital and Disaster Medicine 1996;11:82-90.
} 
The participants in the Gothenberg Congress included:

\section{Chairperson: \\ Knut Ole Sundnes \\ Baerum, Norway \\ Jakov Adler \\ United Nations Headquarters \\ New York and Israel \\ Richard Alderslade \\ WHO \\ Copenhagen, Denmark}

Wahid Al Kharusi

Sultanate of Oman

\section{Bishara Atiyeh}

Beirut, Lebanon

\section{John Barrett}

Asian Disaster Preparedness Center/Asian Institute of Technology

Pathumthani, Thailand

\section{Marvin L. Birnbaum}

Prehospital and Disaster Medicine Madison, Wisconsin USA

\section{Richard Bissell}

National Center for Trauma and Emergency Medical Services Baltimore, Maryland USA

Frederick M. Burkle, Jr.

University of Hawaii

Honolulu, Hawaii USA

\section{Johan Calltorp}

Nordic School of Public Health

Göteborg, Sweden

José da Cruz

The Red Cross Folk College

Mariefred, Sweden

\section{Wolfgang Dick}

Klinik für Anästhesiologie Johannes Gutenberg Universität Mainz, Germany

\section{Albert K. Ekue}

Centre PanAfricain de Prospective Sociale

Porto Novo, Benin

\section{Jean Marie Fonrouge \\ Hôpital Universitaire Edouard Herriot \\ Lyon, France}

\section{S. William A. Gunn}

World Association for Disaster and Emergency Medicine

Geneva, Switzerland

\section{Brian Gushulak}

International Organization for Migration

Geneva, Switzerland

Jennifer Jaumotte

Heinz School of Public Policy and Management

Pittsburgh, Pennsylvania USA

Omar Khatib

Organization of African Unity

Addis Ababa, Ethiopia

\section{Leo Klein}

Purkinje Military Medical Academy Czech Republic

Mark A. Klyachko

Centre for Disaster Prevention and Safe Urban Development

St. Petersburg, Russia

Joachim Kreysler

International Federation of the Red Crescent

Geneva, Switzerland

\section{Jeffrey Levett}

National School of Public Health

Athens, Greece

\section{Kristian Lexow}

Norwegian Society of Disaster Medicine

Stavanger, Norway

Alessandro Loretti

PanAfrican Emergency Training Centre

Addis Ababa, Ethiopia

\section{Gujón Magnússon}

Nordic School of Public Health

Göteborg, Sweden

\section{Michele Masellis}

Mediterranean Club for Burns and Fire Disasters

Palermo, Italy

\section{Matti Mattila}

Nordic Society for Disaster Medicine

Kupio, Finland

\section{Eric K. Noji}

Centers for Disease Control and Prevention

Atlanta, Georgia USA

\section{Dr. Idris Nur}

Organization of African Unity

Addis Ababa, Ethiopia

\section{Chief Segun Olusola}

African Refugees Foundation

Lagos, Nigeria

\section{Pierre Perrin}

International Committee of the Red Cross

Geneva, Switzerland

\section{Jean Luc Poncelet}

Coordinador Programa de Desastres para America del Sur

Quito, Equador

\section{Ernesto Pretto}

Safar Center

Pittsburgh, Pennsylvania USA

\section{Kolawole Raheem}

African Refugees Foundation

University of Jyväskylä

Jyväskylä, Finland

\section{Abdul Radjak}

The Indonesian MH Thamrin Institute of Health Sciences

Jakarta, Indonesia

\section{Edmund Ricci}

Graduate School of Public Health/University of Pittsburgh

Pittsburgh, Pennsylvania USA

\section{Leonid Roshal}

Department of Urgent Surgery

Moscow, Russia

\section{Margareta Rubin}

Swedish National Board of Health and Welfare

Stockholm, Sweden

\section{Debarati Guha Sapir}

Dept. de Santé Publique Lovaine Catholic University

Bruxelles, Belgium

\section{Elena Tivadze}

Referent International Charitable Fund

Children's Hospital

Moscow, Russia

\section{Naruo Uehara}

International Medical Center of Japan

Toyama, Shinjuku-ku

Tokyo, Japan

\section{Karl Axel Wallman}

Nordic Society of Disaster medicine Tygelsjö, Sweden

\section{Harsh Wardhan}

New Delhi, India

\section{Yukihiro Wato}

Tottori University Medical School

Tottori-ken, Japan

\section{Jurgen Weyand}

International Federation of Red Cross and Red Crescent Societies

Geneva, Switzerland

\section{Klaus Wiersing}

United Nations Department of

Humanitarian Affairs

Geneva, Switzerland

Dawit Zawde

The African Humanitarian Action Addis Ababa, Ethiopia 